\title{
Evolutionary investment network and the emerging energy power in Central Asia: From the perspective of cross-border mergers and acquisitions
}

\author{
HE Ze $e^{1,2,3,4}$, CHONG Zhaohui ${ }^{5},{ }^{*}$ YANG Yu ${ }^{1,2,3}$, ZHOU Yannan ${ }^{1,2,3}$, LIU Yi $i^{1,2,3}$
}

1. Key Laboratory of Regional Sustainable Development Modeling/Institute of Geographic Sciences and Natural Resources Research, CAS, Beijing 100101, China;

2. College of Resources and Environment, University of Chinese Academy of Sciences, Beijing 100049, China;

3. Institute of Strategy Research of Guangdong-Hong Kong-Macao Greater Bay Area, Guangzhou 510070, China;

4. Department of Human Geography and Spatial Planning, Utrecht University, Utrecht 3584CB, Netherlands;

5. Shantou University Business School, Shantou 515063, Guangdong, China

\begin{abstract}
Central Asia is emerging as an important pole of global economic and political power, thanks to its unique location at the heart of Eurasia and its abundance in energy reserves. This study explores the social power change in Central Asia from the perspective of cross-border mergers and acquisitions (M\&A) by using the social network method. The main results are as follows: (1) The complexity of the energy M\&A network has significantly decreased after the financial crisis in 2008. In the meantime, energy M\&A became an important way to enhance energy power for buyer countries. Betweenness centrality is becoming the most significant factor affecting energy power, yet the effect of out-degree is weakening. (2) The community underwent multifaceted restructuring, which reflected the shift of energy power in Central Asia. Kazakhstan is the most powerful country in the energy sector in Central Asia. In addition, East Asian countries/regions, represented by China, are actively enhancing their energy power. (3) Different M\&A modes reflect various M\&A motivations of countries in the energy sector. In the future, more efforts should be made to promote the establishment of a pragmatic and efficient multilateral energy cooperation mechanism and strength the cooperation of the economy and energy finance when China participates in the energy market in Central Asia.
\end{abstract}

Keywords: energy power; mergers and acquisitions; evolutionary characteristic; dynamic bargaining; Central Asia

\section{Introduction}

Power is defined as the ability of an agent to influence others or potential to control others' actions (French et al., 1959; Turner, 2005). As an academic theme of international politics

Received: 2020-03-21 Accepted: 2020-07-22

Foundation: The Strategic Priority Research of the CAS, No.XDA20040400; National Natural Science Foundation of China, No.41871118, No.42022007; China Scholarship Council, No.201904910633

Author: He Ze (1992-), PhD Candidate, specialized in economic geography of energy. E-mail: heze@1zb.ac.cn

"Corresponding author: Yang Yu (1984-), PhD and Professor, specialized in energy geopolitics and regional development. E-mail: yangyu@igsnrr.ac.cn 
and sociology, power provides an important perspective for the studies of energy geopolitics, energy security, and global energy governance (Bridge, 1997; Xu, 2012; Xu, 2017). In practice, a deep understanding of the social power could provide the chance to adjust and optimize the international allocation in the energy sector. Such optimization could maximize national interest in the global economic landscape and ensure energy security (Hosman, 2009; Yu, 2011).

Driven by the zero-sum game theory of geopolitics in the early days, the principles of egoism were enshrined in the international energy scramble, which led to long-term chaos in the international order. Competition for the control of scarce resources is not a new phenomenon, and it has been a cause of conflict or war in history (Bo Henpeck, 1976). Since the commercial exploitation of crude oil in Pennsylvania in 1859, the competition around oil resources and channels has resulted in competition for energy. This marks the formation of the early game of energy geopolitics and the struggle for power (Melvin, 1978). Scarcity and the uneven distribution of energy underscore its geopolitical properties, which has a huge influence on global politics and economy (Yu, 2011). Many events, such as the Gulf War, the Iraq war, and the competition for gas pipelines in the Central Asia-Caspian region, reflect the game of power over energy (Brzezinski, 1988; Klare, 2002; Tuncay, 2003; Babali, 2004; Daniel, 2009; Engdahl, 2012; Yang et al., 2015). Moreover, energy power has manifested in the refining capacity and ability to set prices during the two oil crises (Guan and He, 2007; Philip, 2008).

The emergence of new factors, such as the progress in science and technology, energy transition and international political objectives, has led to the change in the behavior of stakeholders from competition to cooperation (Keohane and Nye, 1973; Manning, 2000; Nye and Welch, 2014; Keohane and Nye, 2000). With the development of globalization, global production network and commodity value chain are becoming an important tool to understand the operation of the economic system (Dicken, 2007; Bridge, 2008; Bridge and Michael, 2017; Breul and Diez, 2018) and the "game of power" between multinational enterprises (MNE) and states (Keohane and Nye, 2000). Consequently, social power in the energy sector is shifting from control right over resources (Engdahl, 2004) to capital, technology, and market (Stevens, 2004; Tordo, 2011). However, up until now, we still have a relatively limited knowledge on the social power embedded in the investment and trade networks (Yang and Dong, 2016; He et al., 2019).

Central Asia, in the heart of Eurasia, is becoming the new stage for the major global capital forces in recent years because of the geostrategic location in the context of energy resources, the relatively stable political ecology, the progress in economic reform and opening-up. According to reports, multinational energy enterprises from more than ten countries have gathered in Central Asia to carry out oil exploration and development, crude oil refining, sales and other activities (Yang et al., 2015). Existing studies mainly focus on the export pattern of oil in Central Asia (Kou Zhong, 2010), development status (Yang, 2006), China's energy-related political status in Central Asia (Li, 2009), development trends (Li and Ouyang, 2008), cooperation prospects (Mao, 2013), cooperation models (Zhao and Fang, 2014; Yang et al., 2015), legal issues (Huang and Xiao, 2016), and institutional defects (Yang et al., 2018). However, to date, few studies have focused on the energy and competition and cooperation among big powers in Central Asia from the perspective of cross-border mergers and 
acquisitions (M\&A). Therefore, Central Asia would be a suitable good case for depicting the social energy power based on cross-border M\&A network.

This paper uses Central Asia as a case study to analyse the evolutionary characteristics of the energy M\&A network. In addition, organization modes of cross-border M\&A in the energy sector would also be identified, taking into consideration industrial chains and country differences. This study aims to provide a scientific basis for policy making to promote practical energy cooperation in Central Asia.

\section{Literature review}

\subsection{What is power, and what is the energy power?}

The word "power" is derived from "potestas" or "potenia" of Latin and originally meant ability. As an objective and widespread social existence, power has always been one of the key research objects of political science, sociology, law, and organizational behavior. Robert Russell, the British philosopher, defined the concept of power rigorously in Power: A new social analysis at first (Russell, 2004). He believed that power is the ability of some people to have expected or foreseen effects on others (Emerson, 1962). Max Weber (2013), the pioneer of sociology, argued that power means the opportunity to carry out its will in a certain social relationship, regardless of the basis on which this opportunity is based and even in the face of opposition. Parsons pointed out that power is not only the attribute of the subject but also it is the attribute of interaction and interconnection in a relational system. At the same time, Parsons viewed power as a system resource (Mann, 2012). Power stems from both individual attributes and formal authority, as well as from vertical division of labor (Ibarra, 1993; Ibarra and Andrews, 1993). Power is a collection of relations of various forces, which is "relationship, network, and field" and is decentralized and pluralistic (Foucault, 2019). In recent research, more and more scholars realize that the operation of the power system cannot be separated from a certain space-time scale, background, and goals (Weller, 2009). Therefore, the power in the global production network refers more to the social influence and control right over the economic behavior of other companies (Dicken and Thrift, 1992), rather than the ability of a country to governing land and affairs (Grewal, 2008).

Some researchers argue that a careful consideration of the processes of "energy power" and its effects on the political landscape could offer new perspectives on the energy geopolitical research (Yang et al., 2015; Xu, 2017). Tracing back to the generation process of energy power, this term originated from "oil power" by Xu Jianshan (2012). Kong elaborated the concept of "oil power" and used it as a new perspective to research the international political landscape in his analysis of geopolitical attributes of crude oil (Kong, 2013). Recent researchers have approached the term "energy power system" from different disciplines (Yang et al., 2015; Xu, 2017). They believe that energy power based on traditional oil production patterns are being reconstituted globally in the era of low oil prices. The energy power would not equal to the oil power generated by the ownership and production of fossil energy. Instead, a multidimensional approach integrating "technology power", "financial power" and "carbon emission power" in the energy sector should be adopted (Xu, 2017; Wang, 2019). Following the definition of power by Foucault (2019), this study redefined the social power in the energy sector as "energy power", that is the "influence" and "control 
right" of an agent on other agents in the network which rely on energy circulation of supply and demand process (Yang et al., 2015; Peng et al., 2018; Peng et al., 2019a, 2019b).

\subsection{How was social power embedded in the cross-border M\&A network?}

According to the portfolio theory of investment-induced factors, directly induced factors of M\&A are the basic motivation that triggers enterprises' foreign investment, including the capital, labor, technology, and management and information (Kangueehi, 2015). However, these factors are not always evenly distributed in space. From the perspective of flow space, the process of M\&A is the result of factors flow ranging from the local to the international scale (Castells, 1999, 2010). The uneven distribution of cognition, organization, industry, and society system will have an important effect on the dynamic process of enterprises' M\&A activities and lead to an asymmetric pattern of M\&A cooperation (Grote and Umber, 2006; Ellwanger et al., 2015; Boschma et al., 2016; Di Guardo et al., 2016). As a result, the occurrence of cross-border M\&A is also closely related to the distance of international relations (Reddy and Xie, 2017; Xie et al., 2017) and market dynamics (Prince et al., 2017; Bonanno et al., 2018; Bimpikis et al., 2019).

The energy sector has a unique industrial pattern and development path due to the scarcity, location fixation, and the natural territorial embeddedness of energy resources. Especially, the oil and gas sector is a typical producer-driven industry, which is the result of the powerful combination of privates, TNC, and state-owned enterprises for joint development (Bridge, 2008; Bridge and Michael, 2017). Consequently, M\&A has emerged as a powerful strategy for "home" countries to enter a "host" country's energy market and avoid conflicts caused by the strategic sensitivity and sovereign attributes of energy resources. The success of cross-border M\&A depends on the process of dynamic bargaining under specific constraints (Moran, 2014). Moreover, each party has a certain "power resource", which forms the basis of the bargaining relationship between the two parties (Dicken, 2007). The underlying factors of "power resources" in dynamic bargaining are mainly generated from interactions among enterprises, industries, and countries. The push factors include the strategic motivation of home country, characteristics of industrial agglomeration and global competition and the pull factors include the relative demand strength (scarcity of energy or market), taxation policy and political climate of the host country, international relations and investment agreements between the host and home country. Under the synergy interaction of pull and push factors, many countries and enterprises are involved in the energy M\&A network.

Moreover, the essence of M\&A is that the buyers aim to obtain strategic opportunities, exert synergies, and scope the economy. The realization of these goals is normally through the acquisition of ownership of the target asset (Zhang and Qi, 2002; Qiu and Fang, 2012). In the meantime, power will be transferred from sales to buyers with the finish of M\&A transactions, leading to the transformation of network structure. In other words, the M\&A network is built on the continuous flow of resources, capital, and control rights between countries and enterprises (Dunning and Lundan, 2008). In the process of factor flow and reorganization, the network connection of a country/industry/enterprise is conducive to the agglomeration of factors. Besides, its central position would help it become the emerging regional/global energy power. Obviously, the evolution characteristics and organization modes also profoundly reflect the thinking and path of the rise of new energy powers since 
power is embedded in the M\&A process. So, it is vital to analyze the evolutionary characteristics and the various patterns of organization mode to deeply understand the process of power transfer and system change (Figure 1).

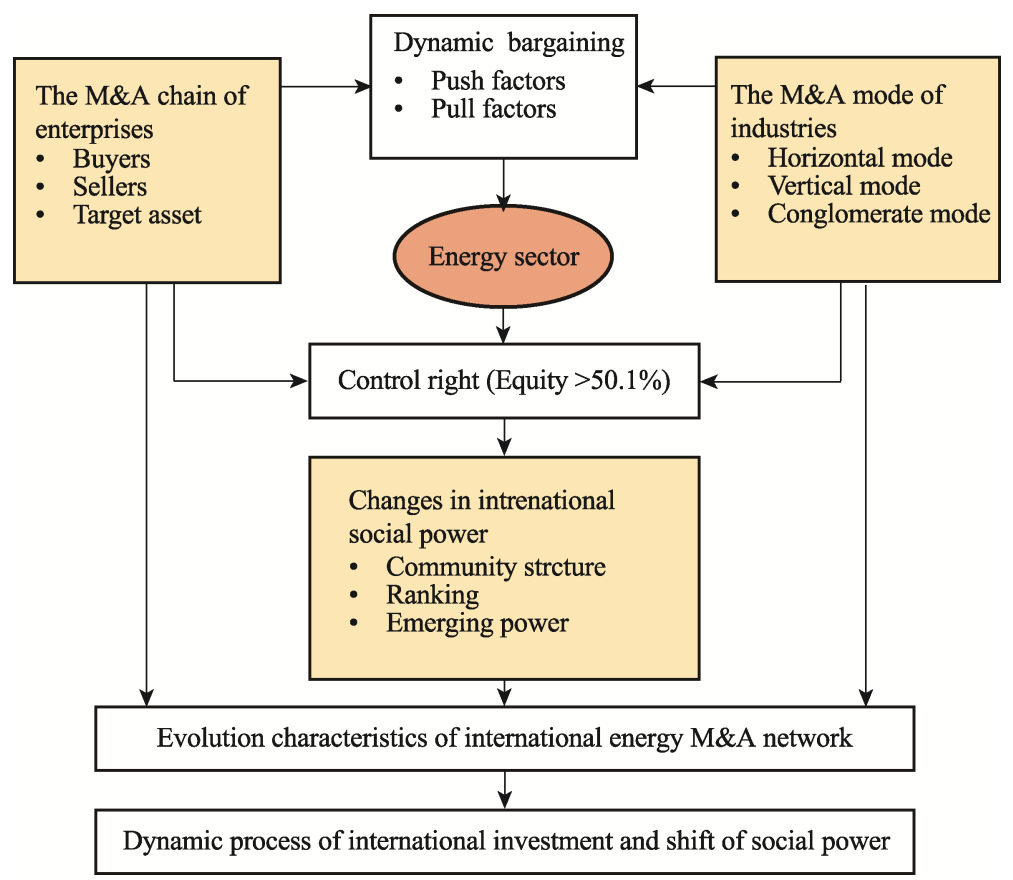

Figure 1 Theory framework of international investment and shift of social power

\section{Materials and methods}

\subsection{Study area}

Central Asia, located in the heart of Eurasia, is usually considered to consist of five countries: Kazakhstan, Turkmenistan, Uzbekistan, Tajikistan, and Kyrgyzstan (Figure 2). According to the BP world energy statistics yearbook 2018, there are approximately four billion tons of oil reserves in Central Asia, accounting for $2 \%$ of the global total. Kazakhstan is the largest country in terms of oil reserves in Central Asia, with 3.93 billion tons in 2017, or accounting for $1.8 \%$ of the total volume of the world and ranking 12 th. Turkmenistan has the largest gas reserves and development capacity in Central Asia. In 2017, its gas reserves stood at 19.5 trillion cubic meters, ranking fourth in the world, with a ratio of storage and production more than 300 years. Compared with the other four countries, Uzbekistan has the least oil resource reserves, but it has a relatively complete gas pipeline network. Since the local consumption of oil and gas is considerably lower than the reserves and their production so that these resources are mainly exported to many foreign countries through international trade.

\subsection{Data}

Data on M\&As were collected from the DealWatch database of the Emerging Markets Information Service (EMIS). The EMIS database is one of the authoritative data sources in 
research on enterprise mergers and acquisitions. It offers information on market dynamics and business information, and research reports of worldwide listed companies.

The process of sample selection is as follows. First, the M\&As completed and Central Asian countries involved were selected from the DealWatch database. According to the International Standard Industrial Classification (ISIC), the enterprises were screened for M\&A by sector for the energy industry, covering the extraction of oil and gas (211), coal mining industry (212), the manufacturing industry for refined oil (324), wholesale of petroleum and products (422), and electric power development (221). The third step is to split a transaction involving different countries into separate transactions. According to company law and securities law, the threshold for absolute control right of target assets transferred through equity transactions in cross-border M\&A is $67 \%$, while the threshold for relative control right of target assets transferred through equity transactions is $50.1 \%$. To better describe the

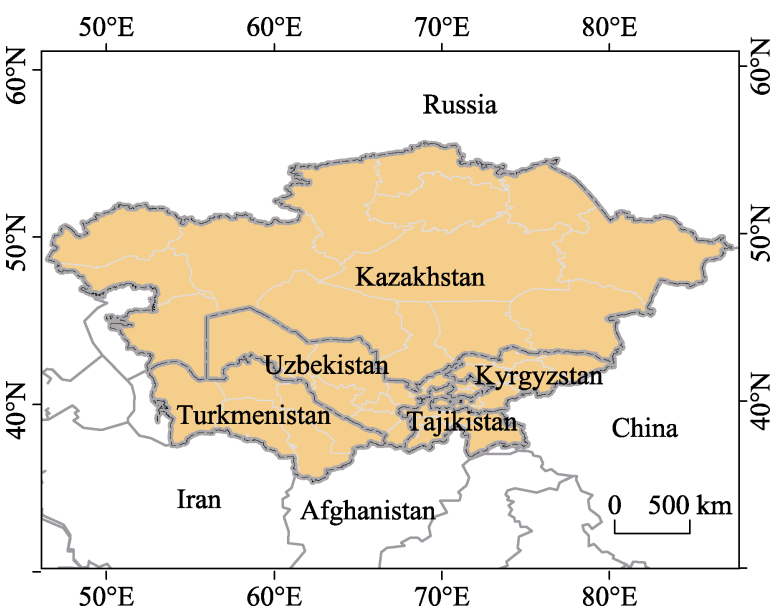

Figure 2 The location map of five Central Asian countries emerging energy power in cross-border M\&A in Central Asia, this study strictly selected samples with target asset equity transactions greater than $50.1 \%$. It is worth to note that the Central Asian countries headed by Kazakhstan did not own the energy industry completely until 2002. Therefore, we set the time period of this study from 2002 to 2016. As shown in Figure 3, the number of energy M\&As relations is 111 and the cumulative value of incomplete statistics is 34,626 million USD during this period.

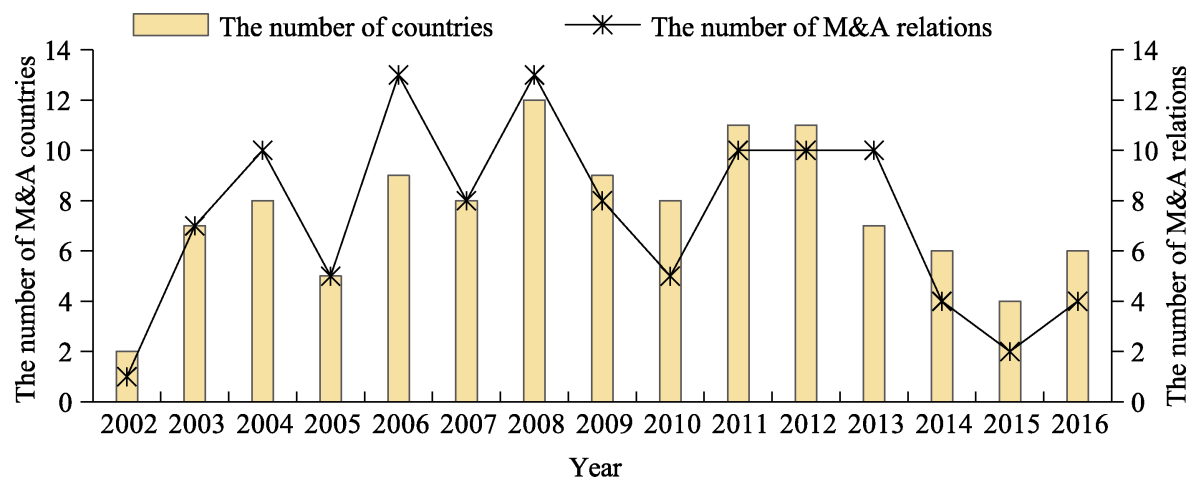

Figure 3 Changes in the numbers of countries/regions and M\&A relations in Central Asia

\subsection{Methods}

This study applies the method of social networks. The main idea of social networks is to symbolize the relationship between the various parts of the system in the form of networks and to explore and show the correlation within the system (Song et al., 2018; Gao et al., 
2019; Liang et al., 2019). In this study, the countries/regions of the M\&A transaction are taken as the nodes, the transaction relations between the countries/regions are taken as the edges, and the directions of acquisitions are taken as the direction of edges (Figure 4). Based on the logic from overall to individual, the evolution characteristics of M\&A network are analyzed.

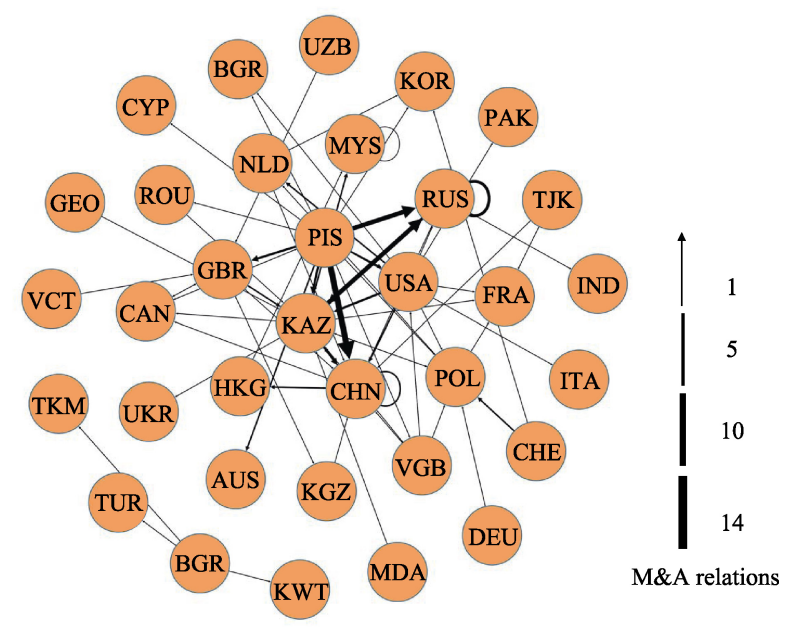

Figure 4 M\&A network in the energy sector in Central Asia

\subsubsection{Overall characteristics}

Stability. The increase and decrease in the number of countries/regions participating in the M\&A network can reflect changes in its stability. According to the definition proposed by Palla et al. (2007), from t to $t+1$ year, if the number of country nodes changes, the formula for measuring network stability is

$$
N S_{t \rightarrow t+1}=\frac{\left|N_{t} \cap N_{t+1}\right|}{\left|N_{t} \cup N_{t+1}\right|}
$$

where $N_{t}$ is the number of countries/regions participating in M\&A in year $t, N_{t+1}$ is the number of countries/regions participating in M\&A in year $t+1,\left|N_{t} \cap N_{t+1}\right|$ is the number of common country nodes between years $t$ and $t+1,\left|N_{t} \cup N_{t+1}\right|$ is the union of country nodes in years $t$ and $t+1 . N S_{t \rightarrow t+1}$ is the value of network stability. Its value is 0 to 1 . The increase in this value indicates a decrease in network diversity and vice versa.

Network density. That is the ratio between the numbers of exited connections and the numbers of theoretical maximum connections (complete graph) in the network. Assume the number of countries involved in the M\&As is $N$, and the number of exited connections is $M$, then the network density calculation formula can be expressed as:

$$
D_{N}=\frac{M}{[N \times(N-1)]}
$$

Average path length. This is a concept in the network topology that is defined as the average number of steps along the shortest paths for all possible pairs of nodes. It is a measure of the efficiency of information or mass transport on a network. $d_{i j}$ is the number of edges 
that the shortest path passing through node $i$ and node $j$, then the calculation formula of average path length $L$ is:

$$
L=\frac{2}{N(N-1)} \sum_{i=1}^{N} \sum_{j=i+1}^{N} d_{i j}
$$

Average clustering coefficient. That is the average probability of two nodes connected to the same node in the network. The clustering coefficient can reflect the degree of network aggregation. Let the aggregation coefficient of node $i$ be expressed as $C L_{i}$, then:

$$
C L_{i}=\frac{2 M_{i}}{k_{i}\left(k_{i}-1\right)}, i=1,2,3, \cdots, N
$$

where $M_{i}$ is the number of edges existing between adjacent nodes and node $i$. Then, the average clustering coefficient $C$ of the network can be calculated as follows:

$$
C=\frac{1}{N} \sum_{i=1}^{N} C L_{i}
$$

\subsubsection{Nodes centrality}

Centrality can be used to depict the role and importance of each country node in the network. Centrality in a directed network is divided into out-centrality and in-centrality, which represents the ability of the node from the perspective of sending and receiving a relationship respectively.

Degree. That includes out-degree and in-degree. As shown in formula (6) and (7), $C_{O, i}$ represents the out-degree of the node $i, l_{i j}$ represents the contact strength of the node $i$ pointing to the node $j, C_{I, i}$ represents the in-degree of the node $i, l_{j i}$ represents the contact strength of the node $j$ pointing to the node $i$.

$$
\begin{gathered}
C_{O, i}=\frac{\sum_{j=1, j \neq i}^{N} l_{i j}}{(N-1)} \\
C_{I, i}=\frac{\sum_{j=1, j \neq i}^{N} l_{j i}}{(N-1)}
\end{gathered}
$$

Closeness. Closeness centrality $\left(C C_{i}\right)$ reflects the degree that a node is not controlled by other nodes in the sending and receiving relationship. Similarly, $d_{i j}$ represents the number of steps in the shortest path from node $i$ to node $j, d_{j i}$ represents the number of steps in the shortest path from node $j$ to node $i$.

$$
C C_{i}=\frac{(N-1)}{\sum_{j=1, j \neq i}^{N} d_{i j}}
$$

Betweenness. That is a measure of brokerage or gatekeeping. The extent to which a particular point lies 'between' other points in the graph and how many shortest paths (geodesics) are there on it. $B C_{i}$ represents the betweenness centrality of node $i$. Here, we assume the number of shortcuts between node $j$ and $k$ is $g_{j k}$, and the number of shortcuts between node $j$ and $k$ through node $i$ is $g_{j k}(i)$, then the control ability of node $i$ to the association between 
node $j$ and $k$ can be defined as $b_{j k}(i)=\frac{g_{j k}(i)}{g_{j k}}$. The formula of betweenness centrality is shown as follows.

$$
B C_{i}=\frac{2 \sum_{j}^{n} \sum_{k}^{n} b_{j k}(i)}{N^{2}-3 N+2}, j \neq k \neq i
$$

\subsubsection{Community structure}

The community structure of the social network refers to the network being composed of numbers of blocs. Each bloc shows a tight connection between nodes while connections between blocs are sparse. To explore the number, composition, and evolution of M\&A blocs can provide a powerful explanation of the behavior of different countries/industries. The modularity proposed by Newman et al. (2006) can measure the degree of network differentiation. The higher the modularity is, the more prominent the network differentiation is, and vice versa. Blondel et al. (2008) designed an algorithm for the division of the community structure based on modularity, and this can be used to divide international M\&A blocs in the network. The range of values of modularity is from -1 to 1 , and the formula is:

$$
\mathrm{Q}=\frac{1}{2 m} \sum_{i} \sum_{j}\left[w_{i j}-\frac{C_{I, j} C_{O, i}}{2 m}\right] \delta\left(c_{i}, c_{j}\right)
$$

where $C_{O, i}$ is the outdegree of country $i, C_{I, j}$ is the indegree of $j, \mathrm{~m}=\sum_{i} C_{O, i}=$ $\sum_{j} C_{I, j}, \delta\left(c_{i}, c_{j}\right)=\left\{\frac{1 c_{i}=c_{j}}{0 c_{i} \neq c_{j}}\right\}, c_{i}$ is the bloc to which country $i$ belongs, and $c_{j}$ is the bloc to which country $j$ belongs. If countries $i$ and $j$ belong to the same bloc, $\delta\left(c_{i}, c_{j}\right)=1$; if not, $\delta\left(c_{i}, c_{j}\right)=0$.

\section{Results}

\subsection{Evolution characteristics of international energy M\&A network in Central Asia}

\subsubsection{The change in stability}

The global financial crisis that occurred in 2008 had a profound impact on global energy M\&A investment, which is consistent with the stability change of energy M\&A network in the Central Asian market (Gopal et al., 2018). Therefore, the time series can be divided into three distinct stages. 2002-2007 is Pre-Recession stage, 2008-2011 is Peak-Recession, while 2012-2016 is Post-Recession stage (Figure 5). During the Pre-Recession stage, the value of stability reached to the peak in 2004 with 0.67 but fell to a low point in 2008 with 0.25. During the Peak-Recession, the number of M\&A relations shows a trend of decrease in fluctuation because these M\&A were concentrated in a limited number of countries. Since 2011, the stability of the M\&A network shows consecutive increases until 2014 thanks to the East Asian and Southeast Asian countries/regions entered the Central Asian market continuously. The number of M\&A relations, and the diversity of participating countries/regions showed a significant upward trend because of globalization and the economic expansion of 
emerging market economies. However, the market was significantly affected by the trend of anti-globalization and the volatility of international oil prices, which depressed the energy M\&A since 2014.

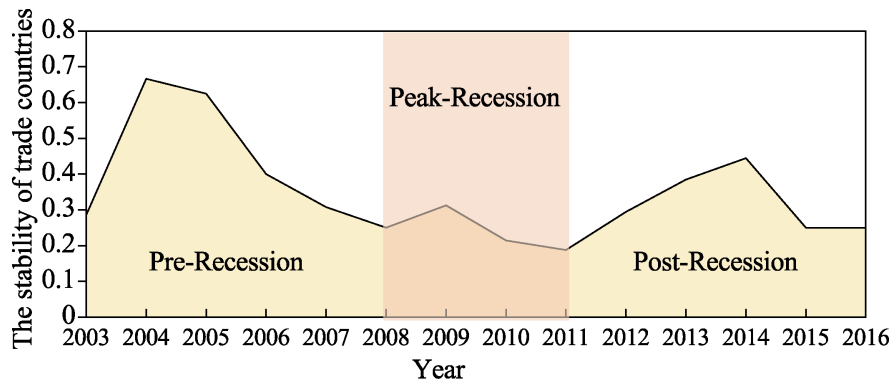

Figure 5 Stability change in energy M\&A network in Central Asia

\subsubsection{The change in network complexity}

Through a comparison of changes in network indicators in the three stages, we can examine the overall characteristic of the M\&A network and its dynamic evolution. What can be seen in Table 1 is the steady decline of all network indicators. The high point values of average path length, the clustering coefficient, and density appeared in the Pre-Recession. In other words, the market concentration and communication efficiency of the network was high. It indicates that the goal of M\&A activities could be realized smoothly because of the small number of countries/regions participating in the Central Asian energy market during the Pre-Recession stage. Compared with the Pre-Recession, the values of network indicators have significantly decreased during the Peak-Recession. During the Peak-Recession period, the network density, average path length, average clustering coefficient, and average degree of the M\&A network were $0.065,1.790,0.062$, and 2.723 respectively. Therefore, the energy M\&A network in Central Asia in the second stage was relatively loose, and its degree of aggregation was worse than that of during the Pre-Recession. In addition, there is much similarity in network indicators between the Post-Recession and the Peak-Recession, which means the complexity of the energy M\&A network in Central Asia has significantly decreased after the financial crisis in 2008.

Table 1 Changes of indicators of energy M\&A network in Central Asia

\begin{tabular}{ccccc}
\hline Stage (Time) & Network density & Average path length & Average clustering coefficient & $\begin{array}{c}\text { Average } \\
\text { degree }\end{array}$ \\
\hline Pre-Recession (2002-2007) & 0.124 & 1.820 & 0.150 & 3.467 \\
Peak-Recession (2008-2011) & 0.065 & 1.790 & 0.062 & 2.723 \\
Post-Recession (2012-2016) & 0.066 & 1.792 & 0.048 & 2.500 \\
\hline
\end{tabular}

\subsubsection{Correlation of degree-degree}

The results of the correlation analysis of degree-degree in energy M\&A network in Central Asia is given in Figure 6. By comparing the results of the different stages, the correlation coefficient between the out-degree and degree continued to decrease from 0.692 to 0.309 , indicating the weakening effects of out-degree. It also reveals that the contribution of asset sales to overall energy power is decreasing. So Central Asian countries cannot only rely on asset sales to maintain or increase their energy power. On the contrary, the correlation co- 


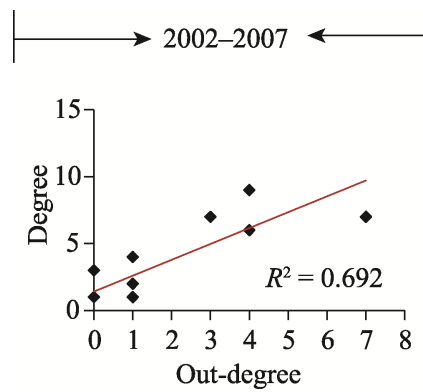

2008-2011
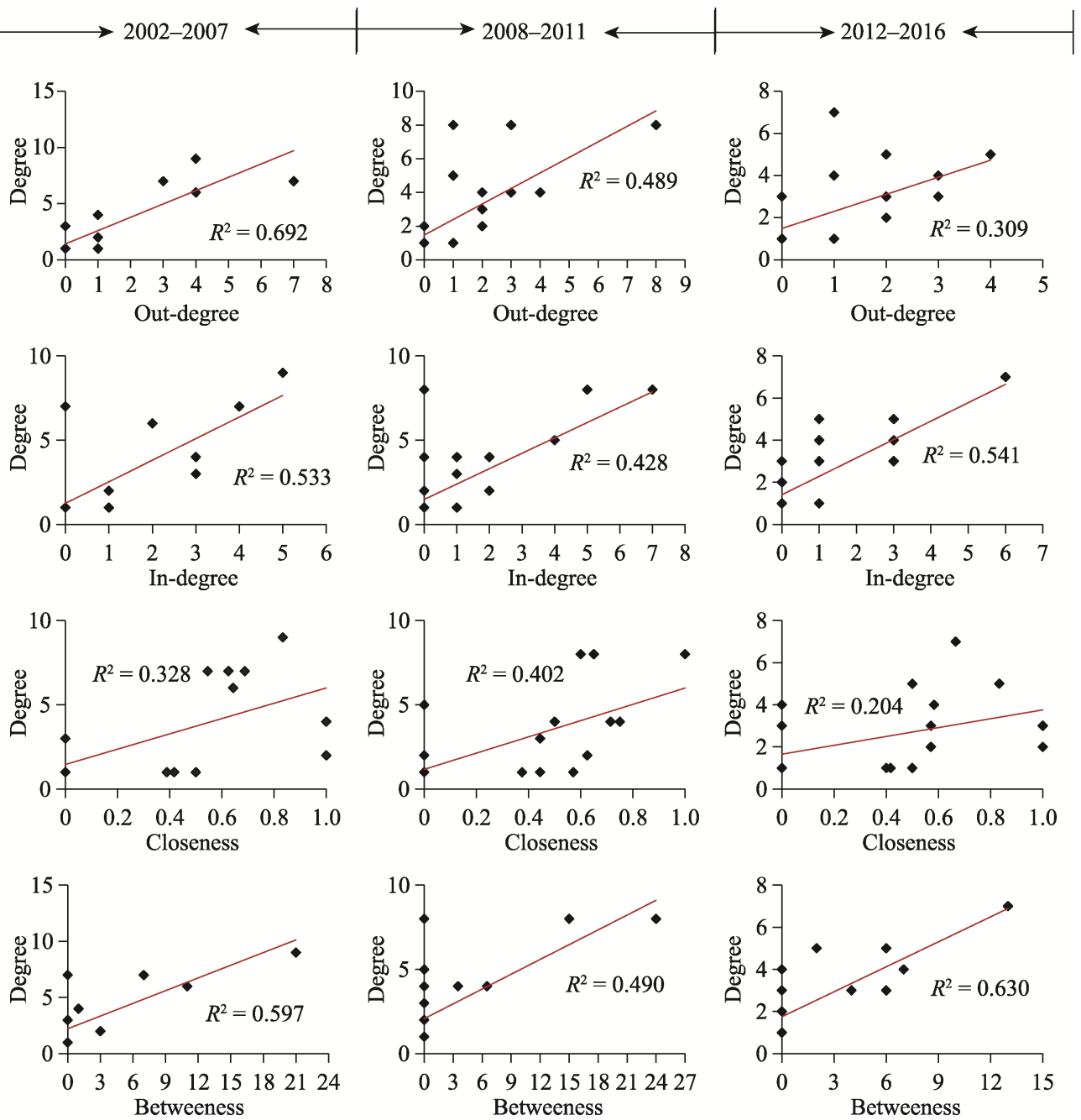

Figure 6 Correlation analysis of degree-degree in energy M\&A network in Central Asia

efficient between the in-degree and the degree is relatively large in all three periods, which shows that energy M\&A is indeed an important way to enhance energy power for these countries. The impact of closeness on these countries' energy power is small and the highest correlation coefficient during the financial crisis is only 0.428 . This may imply that European and American countries have occupied the Central Asian market a long time ago. Meanwhile, the financial crisis in 2008 has accelerated its energy asset sales in Central Asia since the correlation coefficient of betweenness and degree is 0.597 before 2008, and its value increased to 0.63 after the financial crisis. This shows that betweenness centrality is becoming the most significant factor affecting energy power.

\subsection{Changes in community structure of energy M\&A network and the importance ranking of countries}

4.2.1 The changes in community structure

To better demonstrate the changes in community structure in the energy M\&A network, 
countries in one bloc are represented by the same color (Figure 7). In terms of quantity, it has been determined that there are 3, 3, and 5 blocs in the Central Asian energy M\&A network in the three stages, respectively. The increasing number of blocs reflects the growth number of power communities participating in energy development in Central Asia. In short, the community structure shows that multilateral cooperation and competition between Kazakhstan, Russia and the United States is the leading factor to the power pattern before the financial crisis in 2008, while European Union, South Korea, India, Canada, China, and Malaysia have also intervened in Central Asian affairs in different ways and tried to achieve their respective goals in Central Asia. With several emerging market countries entered Central Asia after the financial crisis in 2008, the community structure was reconstructed. On the one hand, other countries in Central Asia, such as Turkmenistan, Uzbekistan, and Kyrgyzstan try to enrich the type and scope of their energy business. On the other hand, the Central Asian countries are beginning to realize "go out", i.e., Turkmenistan and neighboring countries (Turkey and Kuwait) have jointly purchased Iraqi oil fields to enter the Middle East market.

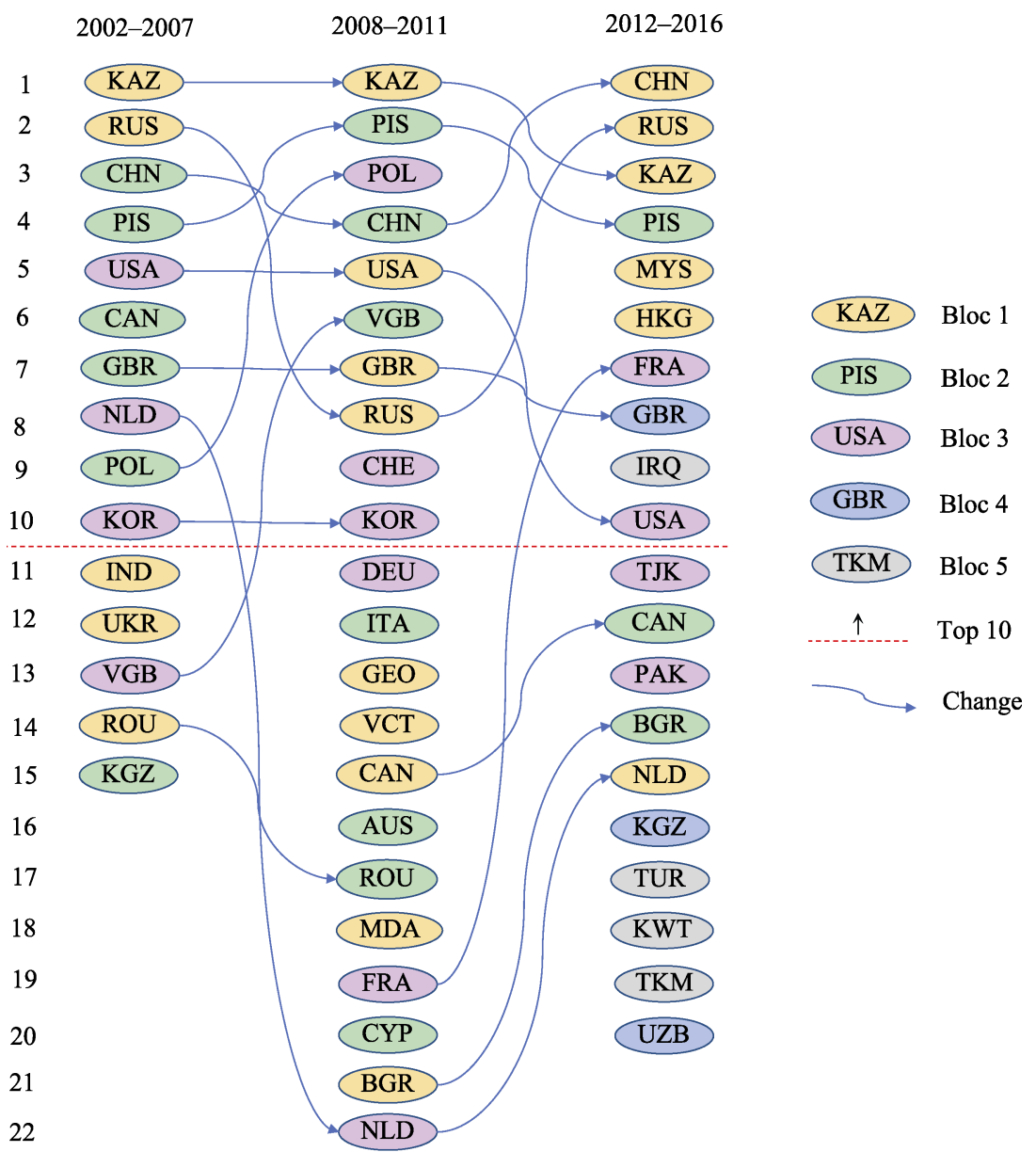

Figure 7 Evolution of blocs' structure of energy M\&A network in Central Asia (for full name, refer to Appendix 1, the same for Figure 8 and Table 2) 


\subsubsection{The ranking of countries and the emerging power}

The value of degree centrality could be used to measure the energy power since the degree centrality is an indicator representing the relative position and role of countries/regions in the M\&A network. As shown in Table 2, the degree centrality of ten top-ranking countries/regions changed in different periods. Through a horizontal comparison of the three stages, we found that Kazakhstan is the most powerful energy country in Central Asia, while Russia and the United States play an important role in the disposal of energy assets. The importance of East Asian countries and regions is on the rise because they are actively seeking to expand their energy business, e.g. Malaysia began cooperating with Central Asian countries in the energy business and China began to buy the equity of energy companies from other countries/regions.

After the collapse of the Soviet Union in 1992, the five Central Asian countries achieved independence one by one. At that time, China was still self-sufficient in energy and had little demand for foreign energy. It thus did not develop its international energy market well. Since 2002, the Central Asian market has been developed by the United States, the United Kingdom, the Netherlands, and other developed countries/regions. It is now difficult for China to enter the Central Asian market. As a result, it took a circuitous path, of buying relatively small and medium-sized energy companies, and scattered equity stakes from private sellers in Central Asia. After the Peak-Recession, the acquisition of energy assets by Chinese companies in Central Asia has continued to increase, and China's energy power has increased significantly so that it even exceeds Kazakhstan.

Table 2 Degree centrality of the top 10 countries (regions) in M\&A network in Central Asia

\begin{tabular}{|c|c|c|c|c|c|c|}
\hline \multirow{2}{*}{ Rank } & \multicolumn{2}{|c|}{ Post-Recession (2002-2007) } & \multicolumn{2}{|c|}{ Peak-Recession (2008-2011) } & \multicolumn{2}{|c|}{ Past-Recession (2012-2016) } \\
\hline & Country/region & Value & Country/region & Value & Country/region & Value \\
\hline 1 & KAZ & 9 & KAZ & 8 & $\mathrm{CHN}$ & 7 \\
\hline 2 & RUS & 7 & PIS & 8 & KAZ & 5 \\
\hline 3 & $\mathrm{CHN}$ & 7 & POL & 8 & RUS & 5 \\
\hline 4 & PIS & 7 & $\mathrm{CHN}$ & 5 & PIS & 4 \\
\hline 5 & USA & 6 & USA & 4 & MYS & 4 \\
\hline 6 & CAN & 4 & VGB & 4 & HKG & 3 \\
\hline 7 & GBR & 3 & GBR & 4 & FRA & 3 \\
\hline 8 & NLD & 2 & RUS & 3 & GBR & 3 \\
\hline 9 & POL & 1 & CHE & 2 & IRQ & 3 \\
\hline 10 & KOR & 1 & KOR & 2 & USA & 2 \\
\hline
\end{tabular}

\subsection{The M\&A modes of energy industries in Central Asia and various motivations}

Furthermore, we counted and classified M\&A relations in Central Asia over 2002-2016 ${ }^{1}$. M\&A modes could be summarized based on the upstream and downstream relations of the industrial chain. If M\&A occurs between the same industries, it is defined as the horizontal

\footnotetext{
${ }^{1}$ We did not conduct a phased discussion in this section because the sample size is relatively small exclude the private sellers.
} 
mode. If M\&A occurs between the industries with upstream and downstream connections, it is defined as a vertical mode. If M\&A takes place in industries that are not directly related, it is defined as a conglomerate mode. For the classification, ISID code, and definitions of upstream and downstream of energy industries in this study, please refer to Appendix 2. There are different motivations and push-pull factors for different countries/regions participating in the Central Asian energy market (Figure 8a). From the industrial chain of M\&A transactions, we can make a primary judgment on the motivations of M\&A.

\subsubsection{Horizontal mode}

Horizontal mode occurred most frequently. The most frequent occurrence of horizontal M\&A shows the flow of energy assets within the oil and gas industry, especially in the oil and gas extraction industry (211). The countries/regions involved in horizontal M\&A can be divided into two categories. One is the combination of countries/regions formed by the sale of assets from Central Asian countries to other countries/regions. These countries include the United States, France, China, Russia, and Canada. From the perspective of Central Asian countries, it is mainly reflected in the pull factors of foreign investment including taxation, improvement of the political climate, and investment agreements between these countries. After attaining from the Soviet Republic, countries in Central Asia found themselves are a nation extremely rich with oil deposits but technologically unable to develop except to help for foreign investment (Hosman, 2009). Kazakhstan took the lead in the process of opening-up in the energy sector, and Uzbekistan and Kyrgyzstan followed suit gradually. Therefore, Kazakhstan has provided tax incentives and improved laws to ensure the improvement of marketization and international cooperation.

The horizontal mode also involves those countries of non-Central Asian countries conduct energy asset transactions in Central Asia. These country or region combinations include the United Kingdom-Canada, the United States-the Netherlands, the United States-China, the United States-Russia, Russia-China, Russia-Russia, China-Canada, and Hong Kong (China)-Malaysia. The pursuit of resources, characteristics of industrial agglomeration, global economic competition, and market profitability are the main motivations for these countries to conduct M\&A transactions. For example, European countries, including the Netherlands, France, Switzerland, Poland, Germany, and Bulgaria play important roles in the country's development of the Central Asian energy market and their participation in obtaining more rights in energy trade.

\subsubsection{Vertical mode}

The vertical mode mainly observes in the upstream and downstream of the same industry. The main performances are the oil and gas exploitation industry (211) and its sub-industries, especially in the oil and gas industry, manufacturing in the refined petroleum industry (324), and wholesale of petroleum and products (422). Although vertical M\&A does not occur as many times as the horizontal mode, the countries (regions) participating in vertical mode are most extensive. It is carried out between China-Hong Kong (China), the United States-Bulgaria, Kazakhstan-Ukraine; China-China and the United States-Poland, British Virgin Islands-Poland, Swiss-Poland, the United States-France, Germany-Poland, Poland-France, Poland-the Netherlands, and Kazakhstan-Poland. One of the possible explanations is that market share and profit targets are the main aims. Among them, some countries 
entered the Central Asian market earlier and have already started to operate the refined oil market in Central Asia.

In addition, vertical M\&A also occurs in the other energy industries, mainly between the mining support industry (213), oil and gas extraction industry (211), electricity, gas and water supply (22), and coal mining industry (212). The cooperation countries are mainly British Virgin Islands-the United States, Kazakhstan-China, and Russia-Kazakhstan. Through the extension of the energy industrial chain, enhancing strategic influence may be one of the key considerations for these countries. Both the United States and Russia are major energy suppliers in the world. They need to achieve global strategy through the manipulation of the energy market in Central Asia. International relationship and geographical proximity are other important factors affecting the scale of factor flow. The closer countries are, the lower the transportation cost of factor flow is, and the greater is the possibility of flow. This is true for Russia and Ukraine. However, historical and cultural factors are superimposed on the pursuit of interest, and the Central Asian countries/regions and Russia have formed a complex mixture of emotions and interests. From the perspective of China, as the biggest energy demand country on the globe, the relative intensity of energy demand is an important driver of energy development in Central Asia. China's energy consumption, especially in industrial energy consumption, promotes the expansion of its external energy market.

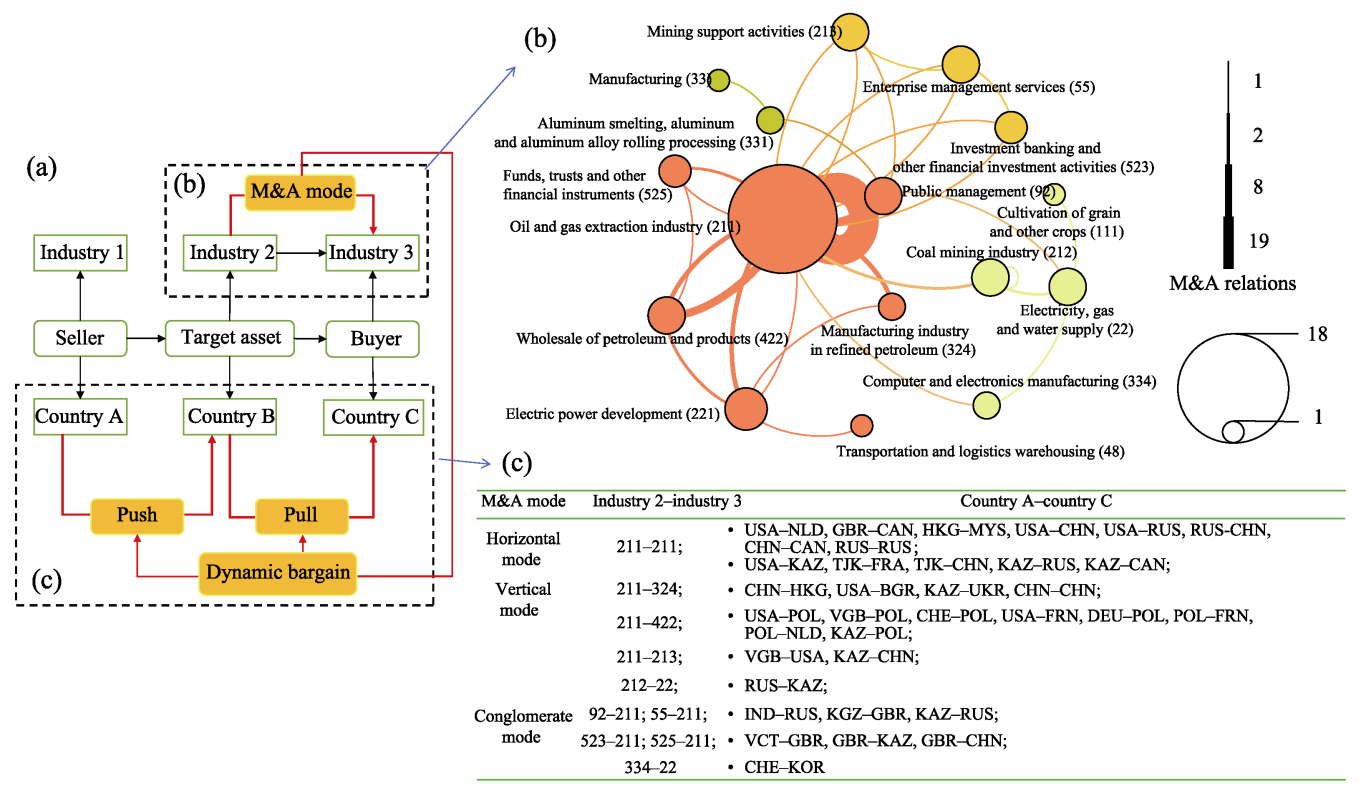

Figure 8 M\&A network relations in the energy sector in Central Asia (2002-2016)

\subsubsection{Conglomerate mode}

In addition, a small amount of conglomerate M\&A was also observed, financial cooperation is the most important motivations for the Conglomerate mode. Specifically, India-Russia, Kyrgyzstan-UK, and Kazakhstan-Russia mainly focused on investment in the oil and gas industry by public management and enterprise management services. St. Vincent and the Grenadines-the United Kingdom, the United Kingdom-Kazakhstan and the United Kingdom-China are mainly devoted to the development of financial investment activities such as 
investment banks and fund trusts in the oil and gas industry. Although there are other possibilities for Bulgaria, the main objective of the British Virgin Islands and Hong Kong of China is a capital orientation for their acting in the energy market in Central Asia, while St. Vincent and the Grenadines, the United Kingdom, and China are committed to the development of investment bank, fund trusts, and other financial investment activities in the oil and gas industry. This reflects the financial capital investment in this area. Specifically, India, Russia, and the United Kingdom focus on investment in public management and business management in the oil and gas industry. Some countries have begun developing diversified industrial embeddedness as they acquire resources by taking advantage of geographical and institutional proximities. For example, LG, a famous company from South Korea, has a wide range of operations in Central Asia and is widely respected and praised in this region.

\section{Conclusions and discussion}

\subsection{Conclusions}

This paper explores the social power change in Central Asia from the perspective of cross-border M\&A, by using the social network method. The main results are as follows:

(1) The global financial crisis in 2008 has a profound impact on global energy M\&A investment, which is consistent with the stability change of energy M\&A network in the Central Asian market. The complexity of the energy M\&A network in Central Asia has significantly decreased since the financial crisis in 2008.

(2) The correlation coefficient between out-degree and degree continued to decrease from 0.692 to 0.309 , which indicates that the effect of out-degree is weakening for energy power. On the contrary, energy M\&A is indeed an important way to enhance energy power for buyer countries. The correlation coefficient of betweenness and degree is 0.597 before the financial crisis in 2008, and its value increased to 0.63 after the financial crisis, so betweenness centrality is becoming the most significant factor affecting energy power.

(3) Changes in community structure reflect that multilateral competition and cooperation is the basis for shaping energy pattern in Central Asia. There are 3-5 groups in the Central Asian energy M\&A network in 2002-2007, 2008-2011, and 2012-2016. The increasing numbers of blocs reflect the growth number of power blocs participating in energy development and investment in Central Asia. Multilateral cooperation and competition between Kazakhstan, Russia, and the United States is the leading factor in the power pattern before the financial crisis in 2008. After the financial crisis in 2008, other countries in Central Asia, such as Turkmenistan, Uzbekistan, and Kyrgyzstan, also tried to enrich the type and scope of their energy business.

(4) Kazakhstan is the most powerful energy country in Central Asia, while Russia and the United States have played an important role in the disposal of energy assets. The importance of East Asian countries and regions is on the rise. The acquisition of energy assets by Chinese companies in Central Asia has continued to increase, and China's energy power has increased significantly after the Peak-Recession so that it even exceeds Kazakhstan. China's investment in Central Asia pursues long-term benefits of strategic opportunities rather than short-term profits. 
(5) M\&A modes could be summarized based on the upstream and downstream relations of the industrial chain. Horizontal M\&A is mainly reflected in the pull factors of foreign investment including taxation, improvement of the political climate, and investment agreements between these countries and Central Asian countries. The most frequent occurrence of horizontal M\&A shows the flow of energy assets within the oil and gas industry, especially in the oil and gas exploitation industry (211). The vertical mode mainly observes the upstream and downstream of the same industry. Although vertical M\&A does not occur as many times as the horizontal mode, the countries participating in vertical mode are most extensive. One of the possible explanations is that market share and profit targets become their main aims. A small amount of conglomerate M\&A also observed financial cooperation is the most important motivation for the Conglomerate mode.

\subsection{Discussion}

This study shows that the Central Asian countries and China are the emerging energy powers in the Central Asiam region. To ensure lasting cooperation between the two parties and further promote mutually beneficial interests, our pieces of advice are shown as follows:

(1) It is important to promote the establishment of a practical and efficient multilateral energy cooperation mechanism. On the one hand, multilateral competition led by big powers has been the key force shaping the energy pattern in Central Asia over the past years. The energy game among Russia and the United States are the traditional leading power shaping the geopolitical pattern. China and Central Asian countries are the emerging power. Other countries/regions, such as the European Union, the United Kingdom, Malaysia, South Korea, India, Canada, and Ukraine have also intervened in Central Asian affairs in different channels to achieve their respective strategical goals. On the other hand, historical experience shows that establishing a practical and efficient multilateral energy cooperation mechanism can effectively help maintain regional energy security and yield collective benefits for the participating countries/regions. It is noted that the framework and agreement of the relevant international energy cooperation in Central Asia are mostly principled, and there is still no substantial energy cooperation framework. Therefore, energy cooperation consultation could be strengthened to form a practical and binding multilateral energy cooperation mechanism under the basic framework of the Belt and Road Initiative in the future.

(2) It is important to strengthen the integrated cooperation mode of the manufacturing industrial development and energy trade. At present, the trade model between China and the Central Asian countries/regions are mainly based on products in exchange for resources. However, this model is not conducive to long-term strategic cooperation and may even increase the possibility of conflicts of interest between the two sides. Most Central Asian countries implement a kind of resource economy with a single heavy industry and a low-level manufacturing industry. Due to the weak manufacturing industry, most of the products are required by Central Asian countries are imported, such as those in the chemical industry, construction, metallurgy, aviation, machinery, and household appliances. Nowadays, Central Asian countries are committed to building and improving their industrial systems. They need foreign technology to support the construction of industrial infrastructure. Therefore, economic ties between China and Central Asian countries can be further stabilized in the future by further strengthening the integrated cooperation of the manufacturing 
industrial development and energy trade.

(3) It is important to increase the diversity of financial services to support the economic development of Central Asian countries. Financial and capital cooperation can significantly promote the establishment of long-term benefit-sharing mechanisms involving Central Asian countries, China, and other countries to maintain long-term strategic cooperative relations. At present, policy development banks, i.e., China Development Bank and the Export-Import Bank of China are the main financial institutions participating in energy cooperation in Central Asia with the method of "loan for resources". Some researchers pointed out that China's global loan unprincipled have increased the debt crisis to these countries (Sum, 2019) while other scholars argued that China's energy investment was a type of "patient capital", especially for those countries cannot start key projects in economic reforms because of lack of capital (Kaplan, 2018). As for China, efforts should be made to increase the diversity of financial services to support the economic development of Central Asian countries. Commercial banks, e.g. the Industrial and Commercial Bank of China, China Construction Bank, Bank of China, China Merchants Bank, and other large domestic commercial banks, should be encouraged to participate in energy cooperation in Central Asia. The Silk Road Fund is an important option to promote investment in high-quality energy assets in this region, especially in the field of construction of the energy infrastructure. Third, companies and private capital should be encouraged to provide overseas financial services and to enhance the overseas reputation of large Chinese energy companies.

This paper has explored the energy power change in Central Asia based on the social network from the perspective of cross-border M\&A. We need to explain again that the energy power studied in this paper is the emerging power generated and transferred in the M\&A process rather than the power in the existing investments and greenfield incitements. Therefore, the results are different from the status in Central Asian energy affairs. Furthermore, the number of relations of energy M\&A network used in the study was limited because of the difficulty of data acquisition. So, more abundant data and detailed empirical cases should be used in future studies to investigate the dynamic process of cross-border M\&A. Lastly, the quadratic assignment procedure (QAP) methods and the Exponential Random Graph Model (ERGM) could be good options to obtain the quantified evaluation mechanism.

\section{Acknowledgements}

We are very grateful to Dr. Dongmiao Zhang of Utrecht University and Dr. Lisa He of the University of Hong Kong for their valuable comments and suggestions on this manuscript.

\section{References}

Bimpikis K, Ehsani S, Ilkiliç R, 2019. Cournot competition in networked markets. Management Science, 65(6): 2467-2481.

Bo H, 1976. Oil and Security. Beijing: The Commercial Press. (in Chinese)

\footnotetext{
2 That means a country's international investment pursues long-term benefits of strategic opportunities rather than short-term profits.
} 
Bonanno A, Russo C, Menapace L, 2018. Market power and bargaining in agri-food markets: A review of emerging topics and tools. Agribusiness, 34(1): 6-23.

Boschma R, Marrocu E, Paci R, 2016. Symmetric and asymmetric effects of proximities: The case of M\&A deals in Italy. Journal of Economic Geography, 16(2): 505-535.

Breul M, Diez J R, 2018. An intermediate step to resource peripheries: The strategic coupling of gateway cities in the upstream oil and gas GPN. Geoforum, 92(6): 9-17.

Breul M, Revilla D, Sambodo M, 2019. Filtering strategic coupling: Territorial intermediaries in oil and gas global production networks in Southeast Asia. Journal of Economic Geography, 19(4): 829-851.

Bridge G, 1997. Mapping the terrain of time-space compression: Power networks in everyday life. Environment and Planning D: Society and Space, 15(5): 611-626.

Bridge G, 2008. Global production networks and the extractive sector: Governing resource-based development. Journal of Economic Geography, 8(3): 389-419.

Bridge G, Bradshaw M, 2017. Making a global gas market: Territoriality and production networks in liquefied natural gas. Economic Geography, 93(3): 215-240.

Castells M, 2010. The Rise of the Network Society: With a New Preface. New Jersey: Wiley-Blackwell.

Castells M, 1999. Grassrooting the space of flows. Urban Geography, 20(4): 294-302.

Daniel Y, 2009. The Prize: The Epic Quest for Oil, Money and Power. London: Free Press.

Di G M C, Marrocu E, Paci R, 2016. The concurrent impact of cultural, political, and spatial distances on international mergers and acquisitions. The World Economy, 39(6): 824-852.

Dicken P, 2007. Global Shift: Mapping the Changing Contours of the World Economy. London: SAGE Publications Ltd.

Dicken P, Thrift N, 1992. The organization of production and the production of organization: Why business enterprises matter in the study of geographical industrialization. Transactions of the Institute of British Geographers, 17(3): 279-291.

Dunning J H, Lundan S M, 2008. Multinational Enterprises and the Global Economy. Massachusetts: Edward Elgar Publishing.

Ellwanger N, Boschma R, 2015. Who acquires whom? The role of geographical proximity and industrial relatedness in Dutch domestic M\&A between 2002 and 2008. Tijdschrift voor Economische en Sociale Geografie, 106(5): 608-624.

Emerson R M, 1962. Power-dependence relations. American Sociological Review, 27(1): 31-41.

Engdahl F W, 2004. A Century of War: Anglo-American Oil Politics and the New World Order. London: Pluto Press.

Engdahl F W, 2012. Syria, Turkey, Israel and the Greater Middle East Energy War. Global Research. Centre for Research on Globalization, 11.

Foucault M, 2019. Power: The Essential Works of Michel Foucault 1954-1984. London: Penguin.

French J, Raven B, Cartwright D, 1959. The bases of social power. Classics of Organization Theory, 7: 311-320.

Gao C D, Guo Q Q, Jiang D et al., 2019. Theoretical basis and technical methods of cyberspace geography. Journal of Geographical Sciences, 29(12): 1949-1964.

Gopal S, Pitts J, Li Z et al., 2018. Fueling global energy finance: The emergence of China in global energy investment. Energies, 11(10): 1-25.

Grewal D S, 2008. Network Power: The Social Dynamics of Globalization. New Haven: Yale University Press.

Grote M H, Umber M P, 2006. Home biased? A spatial analysis of the domestic merging behavior of US firms.

Working Paper Series: Finance \& Accounting No.161. Retrieved from http://hdl.handle.net/10419/23427.

Guan Q Y, He F, 2007. China's energy security and international energy cooperation. World Economy and Politics, (11): 45-53. (in Chinese)

He Z, Yang Y, Liu Y et al., 2019. Evolution characteristics of global energy trading network and relationships between major countries. Progress in Geography, 38(10): 1621-1632. (in Chinese)

Hosman L, 2009. Dynamic bargaining and the prospects for learning in the petroleum industry: The case of Ka- 
zakhstan. Perspectives on Global Development and Technology, 8(1): 1-25.

Huang M, Xiao X, 2016. The legal issues and countermeasures of China's investment in Central Asia. Journal of Changsha University of Science \& Technology (Social Science), 31(2): 160-166. (in Chinese)

Ibarra H, Andrews S B, 1993. Power, social influence, and sense making: Effects of network centrality and proximity on employee perceptions. Administrative Science Quarterly, 277-303.

Kangueehi N C, 2015. Mergers and acquisitions as a strategy for business growth: A comparative overview [D]. Cape Town, South Africa: University of the Western Cape.

Kaplan S B, 2018. The rise of patient capital: The political economy of Chinese global finance. Available at SSRN 3108215.

Keohane R O, Nye J S, 1973. Power and interdependence. Survival, 15(4): 158-165.

Keohane R O, Nye J S, 2000. Globalization: What's new? What's not? (And so what?). Foreign Policy, 118: 104-119.

Klare M, 2002. Resource Wars: The New Landscape of Global Conflict. Boston: Holt Paperbacks.

Kong B, 2013. Oil power: A new perspective of oil geopolitics [D]. Beijing: China Foreign Affairs University.

Kou Z, 2010. New pattern of oil and gas resources export in Central Asia. International Oil Economy, 18(5): 39-47. (in Chinese)

Li H Q, Wang L M, Lang Y H, 2009. Evolution process and driving mechanism of energy geopolitical pattern. World Regional Studies, 18(4): 56-65. (in Chinese)

Li Z, Ouyang D, 2008. The cooperation and development of oil and gas resources in Central Asia and energy security of China. Finance \& Economics of Xinjiang, (5): 61-66. (in Chinese)

Liang Y T, Zhou Z K, Liu Yi, 2019. Location choices of Chinese enterprises in Southeast Asia: The role of overseas Chinese networks. Journal of Geographical Sciences, 29(8): 1396-1410.

Mann M, 2012. The Sources of Social Power, Vol.3, Global Empires and Revolution, 1890-1945. New York: Cambridge University Press.

Manning R, 2000. The Asian Energy Factor: Myths and Dilemmas of Energy, Security and the Pacific Future. New York: Palgrave.

Mao H Y, 2013. Prospects of energy cooperation of China with Russia and Central Asian countries. Progress in Human Geography, 32(10): 1433-1443. (in Chinese)

Melvin AC, Fern R G, 1978. The Geopolitics of Energy. Boulder: Westview Press.

Moran T H, 2014. Multinational Corporations and the Politics of Dependence: Copper in Chile. Princeton: Princeton University Press.

Nye J S, Welch D A, 2014. Understanding Global Conflict \& Cooperation: Introduction to Theory \& History. Pearson Education.

Palla G, Barabási A L, Vicsek T, 2007. Quantifying social group evolution. Nature, 446(7136): 664-667.

Peng P, Poon J P, Yang Y et al., 2019b. Global oil traffic network and diffusion of influence among ports using real time data. Energy, 172: 333-342.

Peng P, Yang Y, Cheng S et al., 2019a. Hub-and-spoke structure: Characterizing the global crude oil transport network with mass vessel trajectories. Energy, 168: 966-974.

Peng P, Yang Y, Lu F, et al., 2018. Modelling the competitiveness of the ports along the Maritime Silk Road with big data. Transportation Research Part A: Policy and Practice, 118: 852-867.

Philip S L, 2008. Oil Geopolitics. Beijing: Social Sciences Academic Press. (in Chinese)

Prince J T, Simon D H, 2017. The impact of mergers on quality provision: Evidence from the airline industry. The Journal of Industrial Economics, 65(2): 336-362.

Qiu L, Fang C L, 2012. Study on the spatial agglomeration of producer services and urban development. Economic Geography, 32(11): 76-80. (in Chinese)

Reddy K S, Xie E, 2017. Cross-border mergers and acquisitions by oil and gas multinational enterprises: Geography-based view of energy strategy. Renewable and Sustainable Energy Reviews, 72: 961-980.

Russell B, 2004. Power: A New Social Analysis. London: Routledge. 
Song Z Y, Che S Y, Yang Y, 2018. The trade network of the Belt and Road Initiative and its topological relationship to the global trade network. Journal of Geographical Sciences, 28(9): 1249-1262.

Sum N L, 2019. The intertwined geopolitics and geoeconomics of hopes/fears: China's triple economic bubbles and the One Belt One Road imaginary. Territory, Politics, Governance, 7(4): 528-552.

Tordo S, 2011. National Oil Companies and Value Creation. Washington, D.C.:World Bank Group.

Turner J C, 2005. Explaining the nature of power: A three-process theory. European Journal of Social Psychology, 35(1): $1-22$.

Wang N Q, 2019. Age of Oil. Beijing: City Press.

Weber M, 2013. From Max Weber: Essays in Sociology. London: Routledge.

Xie E, Reddy K S, Liang J, 2017. Country-specific determinants of cross-border mergers and acquisitions: A comprehensive review and future research directions. Journal of World Business, 52(2): 127-183.

$\mathrm{Xu}$ J H, 2012. Oil power: The core of oil geopolitics. World Economy and Politics, (12): 115-132. (in Chinese)

$\mathrm{Xu}$ Q H, 2017. China's global energy strategy: From energy strength to energy power. People's Forum A Academic Frontiers, (5): 62-68. (in Chinese)

Yang L, 2006. Development status of oil and gas resources in Central Asia countries. Russian, Central Asian and Eastern European Market, (9): 14-18. (in Chinese)

Yang Y, Dong W, 2016. Global energy networks: Insights from headquarter subsidiary data of transnational petroleum corporations. Applied Geography, 72: 36-46.

Yang Y, He Z, Liu Y, 2018. Global energy cooperation Between China and Central Asia: Current situation, risks, and countermeasures. Bulletin of Chinese Academy of Sciences, 33(6): 575-584. (in Chinese)

Yang Y, Liu Y, Jin F J, 2015. Study on energy cooperation between China and the Central Asia and Russia under the view of energy geopolitics. Geographical Research, 34(2): 213-224. (in Chinese)

Yu J H, 2011. World Energy Politics and China's International Energy Cooperation. Changchun: Changchun Press. (in Chinese)

Zhang W, Qi A T, 2002. The review on corporate mergers and acquisitions theory. Nankai Business Review, (2): 21-26. (in Chinese)

Zhao Y B, Fang C L, 2014. Analysis on pattern and prospect of the cooperation of oil and gas resources between China and Central Asia. World Regional Studies, 23(1): 29-36. (in Chinese) 
Appendix 1: ISO3 short name and full name lists of countries/regions in this study

\begin{tabular}{|c|c|c|c|}
\hline ISO3 & Full name & ISO3 & Full name \\
\hline AUS & Australia & KWT & Kuwait \\
\hline BGR & Bulgaria & MDA & Republic of Moldova \\
\hline CAN & Canada & MYS & Malaysia \\
\hline CHE & Switzerland & NLD & The Netherlands \\
\hline $\mathrm{CHN}$ & China & PAK & Pakistan \\
\hline CYP & Cyprus & PIS & Private \\
\hline DEU & Germany & POL & Poland \\
\hline FRA & France & ROU & Romania \\
\hline GBR & United Kingdom & RUS & Russian Federation \\
\hline GEO & Georgia & TJK & Tajikistan \\
\hline HKG & Hong Kong SAR, China & TKM & Turkmenistan \\
\hline IND & India & TUR & Turkey \\
\hline IRQ & Iraq & UKR & Ukraine \\
\hline ITA & Italy & USA & The United States of America \\
\hline KAZ & Kazakhstan & UZB & Uzbekistan \\
\hline KGZ & Kyrgyzstan & $\mathrm{VCT}$ & St. Vincent and the Grenadines \\
\hline KOR & Republic of Korea & VGB & British Virgin Islands \\
\hline
\end{tabular}

Appendix 2: Industry classification in this study

\begin{tabular}{llcl}
\hline \multicolumn{1}{c}{ Industry } & \multicolumn{1}{c}{ Representative industries in this study } & ISIC code & Position \\
\hline \multirow{3}{*}{ Oil and gas industry } & Oil and gas extraction industry & 211 & Upstream \\
& Manufacturing in the refined petroleum industry & 324 & Downstream \\
& Wholesale of petroleum and products & 422 & Downstream \\
\hline \multirow{5}{*}{ Coal industry } & Coal mining industry & 212 & Upstream \\
\hline \multirow{2}{*}{ Energy supply and service } & Eining support industry & 213 & Downstream \\
\hline & Public management & 22 & Downstream \\
& Enterprise management services & 92 & - \\
\hline \multirow{2}{*}{ Others } & Investment banking and other financial invest- & 55 & - \\
& ment activities & 523 & - \\
& Funds, trusts, and other financial instruments & 525 & - \\
\hline
\end{tabular}

